\title{
Research
}

Paper

\section{Neuropharmacological effects of alfa-cypermethrin in rats}

\author{
S. Manna, D. Bhattacharyya, T. K. Mandal, S. Dey*
}

\begin{abstract}
Department of
Pharmacology, University College of Medicine, Calcutta University, 244-B, A. J. C. Bose Road, Kolkata - 20. and Department of Pharmacology and Toxicology, West Bengal University of Animal and Fishery Sciences, 68, K. B. Sarani, Kolkata - 37.

*Chittaranjan National Cancer Research Institute, Kolkata, India

Received: 25.8.2003

Revised: 30.9.2003

Accepted: 7.4.2004

Correspondence to:

S. Manna

E-mail: skmv2@rediffmail.com
\end{abstract}

\begin{abstract}
Objective: To study the effect of $\alpha$-cypermethrin $(\alpha-\mathrm{CP})$ on some neuropharmacological paradigms like motor coordination, pentobarbitone-induced sleeping time and pentylenetetrazole-induced (PTZ) convulsion as well as $\gamma$-aminobutyric acid (GABA) level in rat brain.

Materials and Methods: Albino Wistar rats were the experimental animals. Different neuropharmacological paradigms like motor coordination (determined by rotarod), pentobarbitone-induced sleeping time and PTZ-induced convulsion were carried out following oral administration of $\alpha-C P$ at two dose levels i.e., $145 \mathrm{mg} / \mathrm{kg}\left(\mathrm{LD}_{50}\right)$ and $14.5 \mathrm{mg} / \mathrm{kg}\left(1 / 10 \mathrm{LD}_{50}\right)$, while the level of GABA in the brain of rats was estimated by HPLC after single-dose oral administration of $\alpha-C P$ at $145 \mathrm{mg} / \mathrm{kg}$. Results: $\alpha-\mathrm{CP}$ induced significant motor incoordination, decreased the time of onset and increased the duration of sleeping time induced by pentobarbitone; and also decreased the time of onset and increased the duration of convulsion induced by PTZ at the dose levels of $145 \mathrm{mg} / \mathrm{kg}\left(\mathrm{LD}_{50}\right)$ and $14.5 \mathrm{mg} / \mathrm{kg}\left(1 / 10 \mathrm{LD}_{50}\right)$ respectively. Further $\alpha-\mathrm{CP}$ decreased brain GABA levels in the cerebellum and in whole brain (except cerebellum) significantly at $L_{50}$ dose level.

Conclusion: A correlation between the effect of $\alpha-\mathrm{CP}$ on central GABA levels and its neuropharmacological effects can be hypothesized.
\end{abstract}

KEY WORDS: Convulsion, GABA, hypnosis, rotarod test

\section{Introduction}

Alfa-cypermethrin ( $\alpha-\mathrm{CP})$ (two of the four cis-isomers of cypermethrin), is the most potent cypermethrin and is being extensively used in agricultural farming, livestock industry and to control household ectoparasites to protect human health. Synthetic pyrethroids like cypermethrin act through GABAgated chloride channels. ${ }^{[1-3]}$ But reports on its pharmacological effects and its modulation of brain GABA levels are scarce. The present study was undertaken to determine its pharmacological effects with relation to its modulation of brain GABA levels, if any.

\section{Materials and Methods}

Animals: Albino Wistar rats of either sex weighing $200 \pm$ $10 \mathrm{~g}$ were used. The animals were fasted overnight with water ad libitum. The Institutional Animal Ethics Committee (IAEC) approved the experimental protocol.

Dose of $\alpha-\mathrm{CP}: \alpha-\mathrm{CP}$ was administered orally at $\mathrm{LD}_{50} 4(145$ $\mathrm{mg} / \mathrm{kg})$ and $1 / 10^{\text {th }} \mathrm{LD}_{50}(14.5 \mathrm{mg} / \mathrm{kg})$ dose levels.

Motor coordination by rotarod test: Dunham and Miya ${ }^{[5]}$ (1956) suggested that skeletal muscle relaxation induced by a test compound could be evaluated by testing the ability of mice or rats to remain on a rotating rod. For this purpose, groups of rats were trained to remain on the rotarod for one min. The animals were discarded and replaced if they failed to do so. Thirty animals were considered and trained on rotarod. The rats were divided into three equal groups-I, II and III comprising 10 animals each. Groups I and II received $\alpha-\mathrm{CP}$ at $\mathrm{LD}_{50}$ $(145 \mathrm{mg} / \mathrm{kg})$ and $1 / 10^{\text {th }} \mathrm{LD}_{50}(14.5 \mathrm{mg} / \mathrm{kg})$ doses orally respectively, dissolved in DMSO (1 ml). Group III received only DMSO $(1 \mathrm{ml})$ and was considered as control. One $\mathrm{h}$ after administration of $\alpha-\mathrm{CP}$ and DMSO, all the groups including control were placed on rotarod and the number of animals falling from the rotarod during the scheduled time (1 min) were counted and the percentage was transformed into probit and compared with the control group.

Pentobarbitone-induced sleeping time: Pentobarbitone-induced sleeping time was evaluated according to the method 
of Turner (1965). ${ }^{[6]}$ Thirty animals were divided into three equal groups containing 10 animals each. Pentobarbitone (Sigma Chemicals, USA) was administered (40 mg/kg, i.p.) one h after oral administration of $\alpha-\mathrm{CP}$ at $145 \mathrm{mg} / \mathrm{kg}$ and $14.5 \mathrm{mg} / \mathrm{kg}$ respectively to animals of Groups I and II and sleeping time was recorded as the period starting with loss and regaining righting reflex (Table 1). The control group (Group III) received DMSO and Pentobarbitone.

PTZ-induced convulsion: Again 30 animals were divided into three equal groups containing 10 animals each. PTZ (Sigma Chemicals, USA) was administered (60 mg/kg, i.p.) one $\mathrm{h}$ after oral administration of $\alpha-\mathrm{CP}$ at $145 \mathrm{mg} / \mathrm{kg}$ and $14.5 \mathrm{mg} / \mathrm{kg}$ respectively, dissolved in DMSO, to animal of Groups I and II. The vehicle (DMSO) and PTZ were given to animals of control Group III. The onset of the induction and duration of tonicclonic convulsions were recorded ${ }^{[6]}$.

Determination of GABA level in brain: Twenty rats were divided into two equal groups comprising 10 animals each. Groups I received $\alpha-\mathrm{CP}$ at $\mathrm{LD}_{50}(145 \mathrm{mg} / \mathrm{kg})$ dose dissolved in DMSO (1 ml). While animals of Group II received only DMSO $(1 \mathrm{ml})$ and were considered as control. After $6 \mathrm{~h}$ of $\alpha-\mathrm{CP}$ administration, the remaining six rats including control were euthanized and brain was collected, immediately divided into two parts, cerebellum and whole brain without cerebellum, and both portions were utilized for the estimation of GABA. GABA has been recognized as a major inhibitory neurotrans-

\section{Table 1}

Effect of $\alpha-C P$ on pentobarbitone (40 mg/kg, i.p.)-induced sleeping time in rats following single-dose oral administration at 145 $\left(L D_{50}\right)$ and $14.5 \mathrm{mg} / \mathrm{kg}\left(1 / 10 L_{50}\right)$ respectively.

\begin{tabular}{|c|c|c|c|}
\hline \multicolumn{2}{|l|}{ Group } & Time of onset (min) & Duration (min) \\
\hline \multicolumn{2}{|l|}{ Pento (control) } & $6.20 \pm 0.28$ & $64.30 \pm 1.06$ \\
\hline \multicolumn{2}{|c|}{ Pento $+\alpha-$ CP $(145$ mg/kg) } & $3.85 \pm 0.40^{\mathrm{a}}$ & $180.70 \pm 2.71^{\mathrm{b}}$ \\
\hline \multicolumn{2}{|c|}{ Pento $+\alpha-$ CP $(14.5 \mathrm{mg} / \mathrm{kg})$} & $4.50 \pm 0.29^{a}$ & $76.60 \pm 3.75^{b}$ \\
\hline \multirow[t]{3}{*}{ One-way ANOVA } & $\mathrm{F}$ & 2.755 & 3.902 \\
\hline & $\mathrm{df}$ & 2,27 & 2,27 \\
\hline & $P$ & $<0.05$ & $<0.01$ \\
\hline
\end{tabular}

Pento: Pentobarbitone, values are mean \pm SD, $\mathrm{n}=10$ in each group, ${ }^{a} P<0.05$, ${ }^{\mathrm{b}} P<0.01$ as compared to control.

\section{Table 2}

Effect of $\alpha-C P$ on pentylenetetrazole (60 mg/kg, i.p.)-induced convulsion in rats following single-dose oral administration at 145 $\left(L D_{50}\right)$ and $14.5 \mathrm{mg} / \mathrm{kg}\left(1 / 10 \mathrm{LD}_{50}\right)$ respectively.

\begin{tabular}{|c|c|c|}
\hline Group & Time of onset (min) & Duration (min) \\
\hline PTZ (control) & $4.40 \pm 0.30$ & $42.80 \pm 1.59$ \\
\hline $\mathrm{PTZ}+\alpha-\mathrm{CP}(145 \mathrm{mg} / \mathrm{kg})$ & $2.95 \pm 0.20^{\mathrm{a}}$ & $99.30 \pm 2.47^{b}$ \\
\hline $\mathrm{PTZ}+\alpha-\mathrm{CP}(14.5 \mathrm{mg} / \mathrm{kg})$ & $3.80 \pm 0.30$ & $44.50 \pm 5.20$ \\
\hline \multirow[t]{3}{*}{ One-way ANOVA } & 6.629 & 4.135 \\
\hline & 2,27 & 2,27 \\
\hline & $<0.05$ & $<0.01$ \\
\hline
\end{tabular}

PTZ: Pentylenetetrazole, Values are mean $\pm S D, n=10$ in each group, ${ }^{a} P<0.05$, ${ }^{\mathrm{b}} P<0.01$ as compared to control. mitter in the central nervous system of all vertebrates. It is found in the mammalian cerebellum, corpus striatum, cerebral cortex and spinal cord. Its role in various neurological and mental disorders has been described.

Several methods for the estimation of GABA levels in biological samples, by high performance liquid chromatography (HPLC), have been published. The present procedure determined the level of GABA by HPLC-ECD following its derivatization with OPA and TBT by the modified method of Allison et al (1984). ${ }^{[7]}$

The following is the reaction:

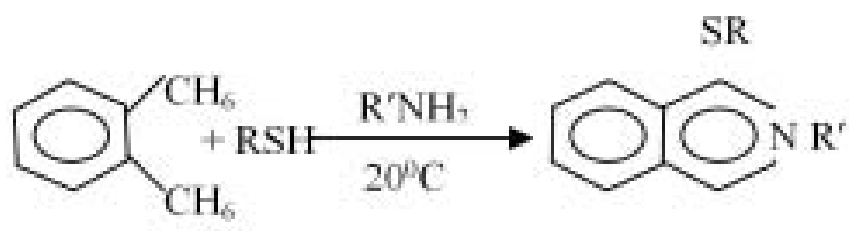

The derivative is a time-substituted isoindole, which is a stable one.

\section{Condition of HPLC}

System: Waters (USA) 464-pulsed electrochemical Detector

Column: Novapak RP-C-18 column (3.9 x $150 \mathrm{~mm})$

Mobile phase: Sodium acetate $(\mathrm{pH} 5)(0.18 \mathrm{M}), 55 \%+$ acetonitrile (v/v), 45\%

Reagents:

1. $0.1 \mathrm{M} \mathrm{HClO}_{4}$

2. GABA stock: $1.2,0.625,0.313$ and $0.156 \mathrm{mM}$

3. $1.0 \mathrm{M}$ Carbonate Buffer

4. Working reagent: $0.0671 \mathrm{~g}$ of OPA dissolved in $50 \mathrm{ml}$ methyl alcohol, to which was added $56 \mathrm{ml}$ of TBT

Procedure: To $500 \mathrm{ml}$ of diluted brain homogenate were added $20 \mathrm{ml}$ of the AVA (5-amino valeric acid) stock (internal standard) and $40 \mathrm{ml}$ of GABA stock and were mixed thoroughly. Working reagent of $800 \mathrm{ml}$ and $200 \mathrm{ml}$ of the above mixture were added to the sample and mixed thoroughly (kept capped to contain the thiol odor). The reaction was allowed to proceed at room temperature for $6 \mathrm{~min}$ and $50 \mathrm{ml}$ of the derivatized sample was injected and run for $15 \mathrm{~min}$. The retention time (RT) of the derivative as well as the unknown sample were found to be at $4.9 \mathrm{~min}$ and $5.1 \mathrm{~min}$ respectively. The data were recorded and analysis was done by Millennium package (Waters). GABA concentration was expressed as mg/gm of wet tissue.

\section{Statistical analysis}

All the values were expressed as mean \pm SEM. Statistical analysis was carried out using SPSS 10.1. Statistical significance of the differences between the two means was assessed by one-way ANOVA followed by Dunnett's test. A probability level of $P<0.05$ was considered significant.

\section{Results}

Pharmacological test: The percentage (of animal present in the rotarod) transformed into probit following single-dose 
oral administration of $\alpha-\mathrm{CP}$ at 145 and $14.5 \mathrm{mg} / \mathrm{kg}$ were 1.98 \pm 0.60 and $5.42 \pm 0.12$ compared to control animals $(6.10 \pm$ 0.150). The one-way ANOVA followed by Dunnett's test was performed, and $\alpha-\mathrm{CP}$ produced ataxia significantly with both $\mathrm{LD}_{50}(P<0.01)$ and $1 / 10 \mathrm{LD}_{50}(P<0.05)$. Table 1 shows that $\alpha-$ CP increased the duration of pentobarbitone-induced sleep time significantly $(P<0.01)$ while decreased the time of onset of sleep at both dose levels. Further, $\alpha-\mathrm{CP}$ increased the duration of tonic-clonic convulsion induced by PTZ significantly $(P<0.01)$ and decreased the time of onset of convulsion significantly $(P<0.05)$ at the dose level of $145 \mathrm{mg} / \mathrm{kg}$ but not at the $1 / 10 \mathrm{LD}_{50}$ dose (Table 2).

Brain GABA level: The concentrations of brain GABA both in the cerebellum and the rest of the brain of rats, following single-dose oral administration of $\alpha-\mathrm{CP}$ at $145 \mathrm{mg} / \mathrm{kg}$ were found to be $1078 \pm 91.25$ and $640 \pm 48.46$ ppm respectively in control animals compared to $218 \pm 35.21$ and $172 \pm 23.01$ ppm respectively in experimental animals. So the brain GABA levels were decreased both in the cerebellum and the rest of the brain significantly $(P<0.01)$ after $\alpha-\mathrm{CP}$ administration.

\section{Discussion}

After 3-5 h of oral administration, the animals showed a closely defined sequence of signs of toxicity like choreoathetosis, loss of righting reflex followed by tonic-clonic convulsion. ${ }^{[8]}$ The rotarod test indicates that $\alpha-\mathrm{CP}$ produces motor incoordination that corroborated with the findings of Crofton and Reitter (1984). ${ }^{[9]}$ The GABA receptor complex is an important target site for Type II pyrethroids like cypermethrin. ${ }^{[10-12]} \alpha-$ CP potentiated the PTZ-induced convulsion in rats. Some GABA antagonists do not interact with the GABA binding site itself but rather with separate sites on or near the chloride channel. Such non-competitive antagonists (like PTZ) block GABA-mediated Cl- flux and therefore act as a potent convulsant. ${ }^{[13]}$ The GABA level is more in the cerebellum than the rest of the brain (i.e. without cerebellum) in control rats. $\alpha-$ CP decreased GABA levels significantly both in the cerebellum and the rest of the brain in treated rats. The decreased GABA level might be either due to decreased synthesis or increased catabolism of GABA resulting in the inactivation of the Cl- channel leading to excitation and convulsion. $\alpha-\mathrm{CP}$ increased pentobarbitone-induced sleeping time in rats. Inversely, pentobarbitone reduced the CNS excitation caused by $\alpha-C P$, which corroborated with the findings of Forshaw et al (2000). ${ }^{[14]}$ Pentobarbitone potentiates GABA-induced chloride conductance and simultaneously depresses voltage activated $\mathrm{Ca}^{++}$currents at lower concentration, but at higher concentration, chloride conductance is increased in the absence of $\mathrm{GABA} ;{ }^{[15]}$ one consequence of the inhibition of these $\mathrm{Ca}^{++}$channels could be the blockade of $\mathrm{Ca}^{++}$entry into presynaptic nerve terminals leading to inhibition of the release of excitatory neurotransmitters such as glutamate. This results in net reduction of excitatory synaptic transmission.

In conclusion it was observed that alfa-cypermethrin potentiates pentobarbitone-induced sleeping time, and PTZinduced convulsion concomitant with the decrease of GABA concentration in the brain.

\section{Acknowledgements}

We acknowledge Dr. A. Hazra, Lecturer of this department for his help in our research work and acknowledge the gift of analytical grade $\alpha-C P$ by $M / S$, Gharda Chemical Ltd., Mumbai, India, to carry out the research work.

\section{References}

1. Lock EA, Berry PN. Biochemical changes in the rat cerebellum following cypermethrin administration. Toxicol Appl Pharmacol 1981;59:508-14.

2. Staatz CG, Bloom AS, Lech JJ. A pharmacological study of pyrethroid neurotoxicity in mice. Pest Biochem Physiol 1982;17:287-92.

3. Gilbert ME, Mack CM, Crofton KM. Pyrethroids and enhanced inhibition in the hippocampus of the rats. Brain Res 1989;477:314-21.

4. Manna S, Bhattacharyya D, Basak DK, Mandal TK. Single oral dose toxicity study of $\alpha$-cypermethrin in rats. Indian J Pharmacol 2004;36:25-9.

5. Dunham NW, Miya TS. A note on a simple apparatus for detecting neurological deficit in rats and mice. J Am Pharm Assoc 1957;46:208-9.

6. Turner RA. Anticonvulsant in: Screening methods in pharmacology. RA Turner editor. New York and London: Academic Press; 1965;1:64-9.

7. Allison LA, Mayer GS, Shoup RE. O-Pthalaldehyde derivatives of amino acids high-speed liquid chromatography/electrochemistry. Anal Chem 1984;56: 1089-96.

8. World Health Organization (WHO). Alfa-cypermethrin. Geneva: Environmental Health Criteria; 1992

9. Crofton KM, Reitter LW. Effects of two pyrethroid insecticides on motor activity and the acoustic startle response in the rat. Toxicol Appl Pharmacol 1984;75:318-28.

10. Salawu OA, lyanniwura TT, Adaudi AO. Effects of anticonvulsants on acute cypermethrin poisoning in mice and rats. Vet Hum Toxicol 2000;42:303-5.

11. Crofton KM, Reitter LW. Pyrethroid insecticides and the GABA receptor complex: Motor activity and the acoustic startle response in the rat. J Pharmacol Exp Ther 1987;243:946-54.

12. Gammon DW, Casida JE. Pyrethroid of the most potent class antagonizes GABA action at the crayfish neuromuscular junction. Neurosci Lett 1983;40:163-8.

13. Varshneya C, Kanwar RS. Pharmacodynamic interactions of cypermethrin and centrally acting drugs in mice. Indian J Physiol Pharmacol 1995;39:154-6.

14. Forshaw JP, Lister T, Ray DE. The role of voltage gated chloride channel in typeIl pyrethroid insecticides poisoning. Toxicol Appl Pharmacol 2000;163:1-8.

15. ffrench-Mullen JM, Barkers JL, Rogawski MA. Calcium current block by (-) pentobarbital, Phenobarbital, and CHEB but not $(+)$ - pentobarbital in acutely isolated hippocampal CA1 neurons: comparison with effects on GABA activated Cl-current. J Neurosci 1993;13:3211-21. 